\title{
Novel Inter-Disciplinary Talent Cultivation Model for Information and Communication Technologies under the One Belt and One Road Background
}

\author{
Yucheng Zhang, a and Wenzhun Huang ${ }^{1, b}$ \\ ${ }^{1}$ Department of Electronic Information Engineering, Xijing University, Xi'an, China \\ a58911533@qq.com, b1051917312@qq.com
}

\begin{abstract}
Keywords: Cultivation model; Information and communication; One Belt and One Road
\end{abstract}
\begin{abstract}
In this paper, we propose the novel inter-disciplinary talent cultivation model for modern information and the communication technologies under the One Belt and One Road background. The communication engineering is a cross a comprehensive strong discipline, electronics and computer is also a physical, practical very strong discipline. Practice teaching and theories teaching complement each other, not only encourage students to apply theory to practice, strengthen the understanding of knowledge, and develop student ability to solve practical problems, improve students' analysis ability and innovation ability. Practice teaching is a key link in the process of communication engineering specialty talents that must attach importance. Under this background, we propose the corresponding research to enhance the traditional cultivation model that is meaningful.
\end{abstract}

\section{Introduction}

With the rapid development of science and technology, on a global scale is given priority to with the science and technology strength and basic economic strength of the comprehensive national strength competition is increasingly intensified, in the long run, and all of the comprehensive national strength competition ultimately embodied in the competition of the national scientific quality. The nation only has the good scientific quality that just can have inexhaustible, inexhaustible intellectual resources. Therefore, in the national vigorously popularize scientific knowledge actively promote the scientific spirit which has the very vital significance [1-3].

According to the literature review, the methodologies of cultivating the innovative talents could be generally summarized as the follows. (1) The innovation of the general innovative talents with strong motivation. So-called innovation motivation can be divided into two aspects of intrinsic motivation and extrinsic motivation, extrinsic motivation refers to the external factors of the innovative desire with intrinsic motivation mainly reflected in the people's interest in the unknown, intrinsic motivation is to realize the innovation of the basic factors and power source. (2) Innovative talents of innovative thinking acuity. Creative thinking is including the unity of logical thinking with the image thinking quality innovative people should have sharp innovative thinking. (3) Innovative talents have a unique way of learning. Innovative talents in the process of knowledge learning, pay more attention to choose to suit their own learning style. In the era of rapid development of science and technology professional knowledge with each passing day, people need to keep learning new knowledge to adapt to society.

Quality is an eternal subject for the development of higher education, as well as the lifeline of the development of higher education. Improve the quality of general talent cultivation and cultivation of high-quality talent is the core task of higher education development, also is the basic requirement of improve the international competitiveness of the higher education in China. Therefore, colleges and the universities personnel training quality standards and talent training quality problem is the focus of many experts and scholars. One Belt and One Road strategy is the symbol of the Chinese Renaissance, the rise of China strategy it is not only the extension of trade routes, but also the extension of national interest security with the border. It not only embodies the contemporary Chinese economic industrial upgrading, industrial transformation brought about by the urgent need, and the more important is the general expression of China's national strategic interests. In the figure one, we demonstrate the related 
path of the strategy. Under this background, we should analyze the corresponding research from the listed perspectives. (1) Cultivate innovative entrepreneurial talent will help ease youth employment pressure. One Belt and One Road along the national youth unemployment has become increasingly serious, develop the students' ability of entrepreneurship and entrepreneurial will effectively ease the students' employment pressure and provide the multiple choices for students better employment. (2) With the further development of globalization, the deepening interdependence among countries in the world politics, international organizations in the fields of both individual issues play an indispensable governance functions. China is an international organization of global governance and an important participant, builder and the contributor to multilateral cooperation [4].

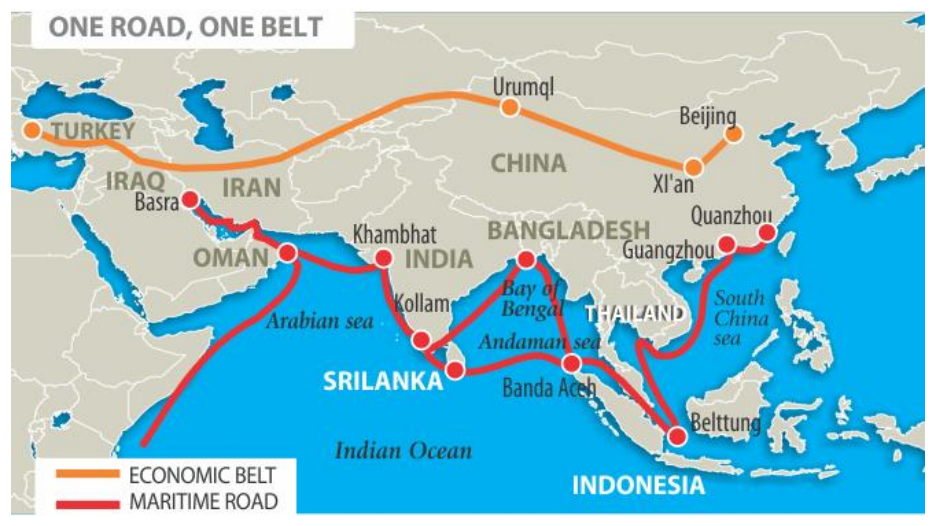

Figure 1. The Principles of the One Belt and One Road

\section{Our Proposed Methodology}

The Education Reform Trend. The 21st century, with the growing international exchanges and the cooperation, comprehensive national strength competition is intense, in especially important position makes colleges and universities. Colleges and universities in the 21 st century should be to train and bring up high quality creative talent's cradle, should be meet the unknown world, to explore objective truth and provide scientific basis for the front, should be the innovation in knowledge, an important force in promoting transformation of general scientific and technological achievements into realistic productivity, should be a national excellent culture to communicate with world advanced civilization achievements for the primary and general reference [5].

With the development of modern information technology, applied to the education of the modern information technology, digital audio-visual technology, satellite radio and the television technology, multimedia computer technology and general artificial intelligence technology, interactive network communication technology and virtual reality simulation technology modern information technology to the field of education, the teaching media has new characteristics, characterized by the multimedia teaching information display, digital teaching information processing, teaching information storage disc and intelligent teaching information transmission network and the teaching process.

Higher education content the contradiction between infinite growth and higher education limited conditionality of time and space is a pair of important contradiction of education activities. Time and space are relatively constant, can't change, therefore, to solve contradiction only from the education goal, content, methods and means of the reform, positive credit-system teaching management, create more flexible learning space for the students, so the only effective way of solving the conflict of the education space and time that will help achieve better significance [6].

The Inter-Disciplinary Talent Cultivation. From the humanities knowledge is the humanistic quality structure, social psychology, personality, culture, humanistic spirit of five aspects. Humanistic quality education is human outstanding culture achievements, through the knowledge, environment influence and its practice, within the temperament, personality and accomplishment that become a relatively stable internal quality. In the era of knowledge economy, knowledge innovation, technology 
innovation and concept innovation, need to have a large number of innovative talents. The scale of the higher education has been among the world top, complete the history of the popularization of higher education goals. The main task of the institutions of higher learning from the number of development into a stage of improving teaching quality, cultivate a large number of the qualified talents for national construction and top-notch talents with innovative ability.

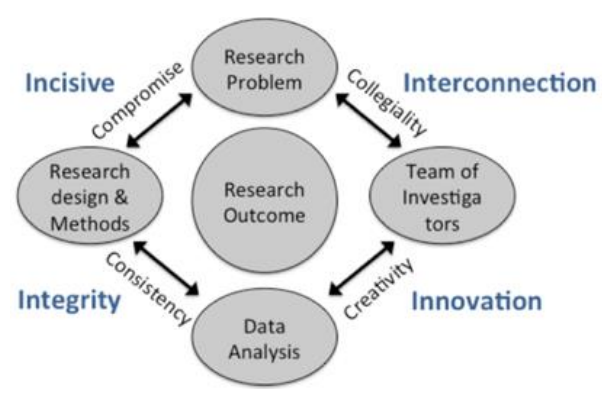

Figure 2. The General Components of the Inter-Disciplinary Talent Cultivation

Personnel training in the colleges and universities should adhere to the people-oriented, promoting person's full scale development of managerial guiding ideology, should be to improve the quality of the knowledge, ability cultivation and is improve the quality of personnel training.

- Because of the rapid development and utilization of the material resources is the basis for the development of human society and human resources development and the utilization degree decides the depth and breadth of for the material resources development. People are the most active productive forces, the most active, the most important factor, is the core elements of the social productive forces development.

- People-oriented core are fully recognized in human nature, to the person's potential and basic wisdom of the trust, give play to the role of human subjectivity. The most widely mobilize all positive factors, the most fully stimulate the creativity of human, maximize human ingenuity, people's initiative and creativity.

- Based on the principle of having both primary ability and political integrity, build based on the performance, made up of moral character, knowledge, ability and other elements of all kinds of talents evaluation index system. Second, as long as the efforts to cultivate and improve their moral character have certain knowledge or skills that is able to carry out creative work [7].

The Information and Communication Technologies. In the new world of information society, the social productivity will largely depend on the spread of the information and processing power, depends on the progress of information technology. Here, the information was expressed in terms of the code, such as analog representation refers to the measurement, calculation, symbols, text, images and sound, etc. Technology refers to the collection, processing, storage, transport, copy, or to express information of any artificial means. In emerging information technology, computer communication technology is one important branch of rapid development.

Accordingly, the information and communication technologies could be reflected from the listed aspects. (1) Assembly technique with computer system reliability, ease of ordinary maintenance and debugging, production technology and information transmission delay of a close relationship. Change of computer electronics, a great impact on the assembly technology, assembly technology is always in harmony with the computer model. (2) Computer technology is faced with a new set of big changes. Neumann of simple hardware and special logic system cannot adapt to the trend of increasingly large and complex software has become increasingly complex, the subject, for creating subject to natural logic of the new system software needs and subject. (3) The computer system is composed of quantity and variety of the part. Various components technology content is very rich, mainly has operation and the control technology, information storage technology and the information input and output, etc. (4) System structure technology is to make the action of the computer system get good problem solving 
efficiency and the reasonable cost performance. System management implemented by the operating system, in order to improve the basic capacity of the machine, the problem solving aging, convenient operation, improve the system reliability and reduce computation cost, etc.

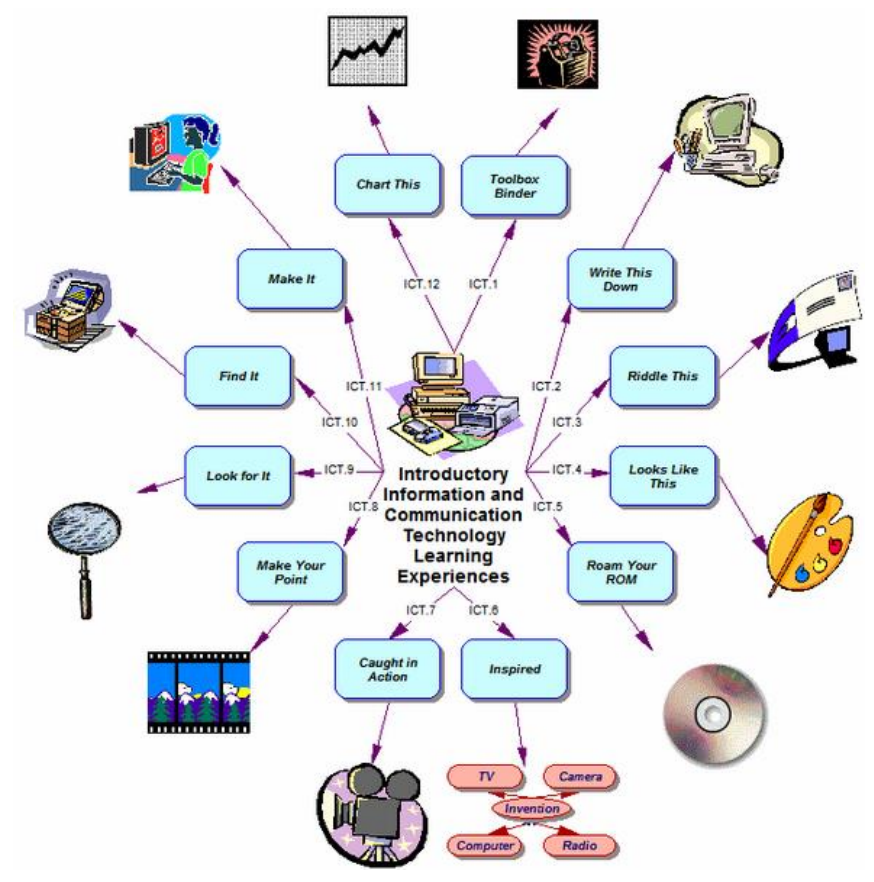

Figure 3. The Information and Communication Technologies

The Communication Talents. Communication engineering professional engineering and general technical project of cultivating applied undergraduate education on students' basic requirements are: the control circuit and signal analysis, communication system, signal transmission and exchange, the basic theory of signal processing; Master this professional direction system of the basic specialized knowledge, has the preliminary hardware design, software design or system design ability; Master the communication network, system, equipment composition and basic principle, as well as the relevant design, production, testing, installation, maintenance, operation and management of the preliminary ability; Solid basic computer knowledge and skilled operation skills, and the computer hardware and software design and development of the preliminary ability. Aiming at the current situation of basic communication engineering professional talent training and existing problems, and we've come to the conclusion that the full range of communication engineering specialty construction strategy [8-9].

- Reform of the teaching methods. We should actively create conditions for the comprehensive promotion, further promote heuristic, the interactive teaching, that fundamentally change the force-feeding teaching still represents a significant share of the status quo, focus on training students' independent thinking and creative thinking; In all kinds of courses, advocates the participatory, heuristic, discussion-based teaching method and research type actively promote the original teaching materials with bilingual teaching.

- To carry out the teaching content and course system of change. To strengthen the construction of key courses, courses and exquisite course construction, deepening the reform of the course system and course content. According to the quality of education and practical, the innovation ability training requirements, according to the characteristics of the different types of courses reform of teaching content.

- To carry out the reform of teaching methods, especially the experiment, the practice teaching link. Actively use modern teaching methods, fully implementing computer aided teaching, encourage teachers to research and development of multimedia courseware and the computer aided teaching software and platform. 
- The reform of the education mode. Change current and the appropriate to the planning system, and appropriate to the stage of elite higher education training mode of "unified purpose", and actively explore with the current national economic and social development situation and get adapt to the development of higher education situation, focus on training students' learning, innovation and practical ability of flexible training mode.

The One Belt and One Road Background. One Belt and One Road to central Asia, South Asia, Southeast Asia, west Asia and other regions, is conducive to the regional exchange, complementary advantages establish and improve the supply chain, industry chain and the value chain in Asia, the pan-Asian and regional cooperation in the Asia and Europe to a new level. In other words, in terms of internal, this can be for China to establish a new economic growth engine, in terms of external, also can make the relevant countries in China, with the help of infrastructure construction, to lay a good foundation for its own economic development. Economic belt "silk road" and "maritime silk road" of the 21 st century, not only means that the Chinese economy to find new sources of growth, and at the same time, more important of China's opening to the outside strategy opened a new chapter of history.

One Belt and One Road strategy involved in the construction of infrastructure, both trade and the investment, industrial cooperation, such as hard power, also involves such as policy, talent, culture soft power. In a sense, the soft power of play to compete rather than hard power. Talent is the pivot of the area along the construction and the key. One Belt and One Road without innovation to achieve the goal of vision and the entrepreneurial talent, talent in the international organizations, the common language talent, overseas Chinese talents, overseas high-level talents as well as be badly in need of the professional talents and so on all kinds of talents in the field of support and guarantee. Face the demands and challenges, education especially higher education department should according to the requirements of area along the strategy to "endogenous" and "extension" is the path, renew the idea, perfect the system, the optimization of running a school, innovation practice, earnestly shoulder the important mission of the talent training.

\section{Summary}

In this paper, we propose the novel inter-disciplinary talent cultivation model for information and the communication technologies under the One Belt and One Road background. For cultivating general innovative high-quality talent, educators must first set up the new talent. Students in colleges and the universities, have to ask for "high quality, creative". Quality contains ideological and moral quality, cultural quality, professional quality and general physical psychological quality; While creativity and innovation spirit and innovation ability, this is eager to quality of talents in colleges and universities in the 21 st century. We according to the theory of the system optimization to seek education theory and education practice, the education management together and benign interaction between the teaching practice, in the process of management system and ensure the index system construction, to promote the continued to carry out innovative education activities, build operable operation mechanism for the innovative talent training mode of the best breakthrough point, in order to realize the cultivation of innovative talents. In the future, we will review more research for theoretical optimization.

\section{Acknowledgements}

This paper was financially supported by Research on real time monitoring system of surface subsidence based on GPS and GPRS, Scientific research fund of Xijing University in 2013, project number: XJ130102.

Research on General issues of teaching reform of Xijing University in 2015, Project name: Research and Practice on the IT Outstanding Engineers Education Training Plan based on University-Enterprise Cooperation Alliance, project number:JGYB1527. 


\section{References}

[1] Chang, Tsen-Yao, and Kuo-Li Huang. "Service-Learning Model of Cultural and Creative Talent Cultivation for the Bamboo Industry Cluster." HCI International 2013-Posters' Extended Abstracts. Springer Berlin Heidelberg, 2013. 479-483.

[2] Gang, D. I. N. G. "Worldwide Talent Cultivation Modes and Their Revelation to Innovative Administrative Management Talent Cultivation in China." China Education of Light Industry 2 (2015): 025.

[3] Zehua, Dong, et al. "Research and Practice on the Role of Fundamental Engineering Chemistry in the Interdisciplinary Talent Cultivation [J]." Higher Education in Chemical Engineering 1 (2013).

[4] Li, Zou. "' 1+4+ 8" education resources integration strategy research based on applied talent cultivation." Special Zone Economy 1 (2014): 038.

[5] Jun, R. E. N. "Practice and Exploration of Inner Mongolia University for Nationalities Strengthen Connotation Construction Teaching and Innovating the Mode of Talent Cultivation." (2014): 006.

[6] LI, Xi-bing, et al. "Application of OICE in the Cultivation of Innovative Talent for Mechanical and Mechatronic Majors [J]." Research and Exploration in Laboratory 2 (2013): 031.

[7] JIA, Rong, and Ruo-chun YIN. "The explorations and practices of the composite applied cultivation of talents mode for biotechnology major in Anhui University." Journal of Biology 1 (2013): 028.

[8] WANG, Sui-lou, et al. "Discussions on the Curriculum Systems and Teaching Contents of Food Quality and Safety Specialty in China Pharmaceutical University Based on the Cultivation of Engineering Bachelor." Academic Periodical of Farm Products Processing 3 (2014): 031. 